\title{
Item analysis -Utility for increase in MCQ validity in biochemistry for MBBS students
}

\author{
Sheel Thorat ${ }^{1 *}$, Madhur Gupta ${ }^{2}$, Madhura Wasnik ${ }^{3}$ \\ ${ }^{1}$ Tutor, ${ }^{2}$ Professor and Head, Dept. of Biochemistry, ${ }^{3}$ Final MBBS, NKP SIMS, Nagpur, Maharashtra, India
}

*Corresponding Author: Sheel Thorat

Email: sheelthorat@gmail.com

\begin{abstract}
MCQ are used more often to assess students of different educational fields for their objectivity. Making a fair analysis of students performance can be a challenging job. Item analysis of MCQ`s is one of the suggested method for analysis. $60 \mathrm{MCQS}$ were randomly selected which were given to $1^{\text {st }}$ M.B.B.S. students in term and prelim exam. Item analysis was done by calculating difficulty index [DIF] and Discrimination index [DI]. In the result we concluded that out of 60, 9MCQS were in very difficult value, 28 in easy and 22 in acceptable. 16 MCQS were in 0.2 discrimination and 46 were in less than .2 discrimination index. So these MCQ`s were fairly distributed in nature.
\end{abstract}

Keywords: MCQs, Biochemistry, Item analysis.

\section{Introduction}

Any academic course is incomplete without assessment. Assessment is an essential part of learning. ${ }^{1}$ Multiple choice questions [MCQs] is the most commonly used method for assessing the knowledge capability of a student. ${ }^{1}$ Often poorly constructed MCQs do not fulfill the requirement of an assessment. A quality assessment of MCQs is known as Item Analysis. Item analysis is especially valuable in improving items which will be used again in later in tests. It can also be used to eliminate misleading items. ${ }^{2}$ Constructing a high quality MCQs can be difficult and time consuming. ${ }^{2}$ MCQs are popular due to their high objectivity and ability to assess large content in short time. They can assess cognitive and psychomotor domain. Assessment by MCQs is the main mode of evaluation in our institution. The MCQs are 'single best response' type with 4 options. THE MCQs had 3 components the stem, key and the distractor. Difficulty index,[p] and discrimination index are parameters used to assess the standard of MCQs. ${ }^{3}$ An additional analysis that is reported is the distractor analysis. The distractor analysis provides a measure of how well each incorrect answer contributes to the quality of the MCQ. Item difficulty is the percentage of students taking the test who answered the item correctly. The higher difficulty index, the easier item understood to be. It has a great effect on test scores and discrimination among different group of examinees. An item that everyone gets incorrect or gets correct will have discrimination index $[\mathrm{DI}]=0 .{ }^{4}$

\section{Aims and Objectives}

1. Is to perform an item analysis of MCQ's for testing their validity as assessment tools.

2. To carry out a post validation item analysis of MCQ's of $1^{\text {st }}$ MBBS students in biochemistry in order to evaluate correlation between item difficulty, item discrimination so as to determine whether question should be included or discarded.

\section{Materials and Methods}

Study was performed in Dept. Of biochemistry at NKP SIMS and Research centre Nagpur. Total 60 MCQS were analysed between June to Nov 2018.The students were listed in decreasing order of marks obtained in respective exam. Before the exams the students were given a fair idea of the exam. Students were divided into high achievers and low achievers. The students who acquired 7 and more marks were included in high achievers or upper group and below 7 were included in low achievers or lower group. The students tick options a, b,c,d were counted in each group. Based on answers marked by students discrimination index, difficulty index was calculated using standard formula. Difficulty index was calculated by the formula $\mathrm{P}=(\mathrm{H}+\mathrm{L} / \mathrm{N}) \times 100$ where $\mathrm{H}$ is the number of students in upper group correctly answering the item and $\mathrm{L}$ is the number of students in lower group correctly answering the item and $\mathrm{N}$ is to total number of students. It is expressed in percentage. Difficulty index was interpretated as follows-30 to $70 \%$ acceptable, above $70 \%$ easy, below 30\%-very difficult. Discrimination Index was calculated by the formula $\mathrm{DI}=2 \times[(\mathrm{H}-\mathrm{L} / \mathrm{N})] \mathrm{H}=$ number of correct responses in upper group. $.^{5} \mathrm{~L}=$ Number of correct responses in lower group, $\mathrm{N}=$ Total number of response in both groups. Discrimination index was interpretated as follows $>.21-.24$ is acceptable, $=<.20$ is poor. 1 . Statistical analysis was performed. All data was expressed as mean + SD. ${ }^{5}$

\section{Result}

9 MCQS were included in very difficult. 28 MCQS were included in very easy and 22 in acceptable. 16 MCQS were in 0.2 discrimination index and 46 were less than .2 discrimination index.

Table 1: Difficulty Index of MCQ's

\begin{tabular}{|l|c|c|}
\hline $\begin{array}{l}\text { Very difficult } \\
\text { Less than } \mathbf{3 0 \%}\end{array}$ & $\begin{array}{c}\text { Acceptable } \\
\mathbf{3 0} \mathbf{7 0 \%}\end{array}$ & $\begin{array}{c}\text { Very easy } \\
\text { Above 70\% }\end{array}$ \\
\hline 9 & 22 & 28 \\
\hline
\end{tabular}


The problem with this type of difficulty index is it does not indicate whether the item is difficult or easy

Table 2: Discrimination Indexof MCQ`s

\begin{tabular}{|l|c|}
\hline More than 0.2 & Less Than 0.2 \\
\hline 16 & 46 \\
\hline
\end{tabular}

\section{Discussion}

Generally speaking item analysis statistics help us to decide which item to keep and which to discard.

In our study, more students in the high achiever group got the item correct than the low achiever group.

DI of an item is its ability to find the difference between students of higher and lower abilities. Here the question can be too easy[[attempted correctly by all] or [done wrongly by all]and it will have nil topoor DI. value of DI ranges from 0to 1 . In such cases students of lower ability answer questions correctly than students of higher abilities items with DI are useless and they decrease the validity of the test. Negative DI can be due to wrong key or poor preparation of students. The results of our study is comparable to findings of the study done by Dr. Vrunda Kolte. $^{6}$

Thus when an item is carefully developed by experienced teachers to suit a particular group of students a much higher percentage of items will be found to be working

Item analysis is very important for it increases in MCQ validity in any subject for the students. MCQS with average difficult index and high discrimination power should be incorporated. An ideal item is which has average difficulty [1 to 31] and high discrimination. Items analysed in the study were neither too easy nor too difficult.

\section{Conclusion}

It is a simple technique but valuable. It can help to develop a valid Question bank with categorisation. Assessment of MCQs by these indices highlights the importance of assessment tools which benefits student and teacher. MCQ pools of all subjects must be critically analysed for quality assessment.

\section{Limitations}

In present study item analysis of only two test was done .A study may be carried out involving teachers who framed MCQs of subject interacting with them the data on one test, improving their items in next test, comparing the data of next test with previous. Feed back from the teachers can be taken along with their experience and improving of the items can be planned. Such a study will evaluate the impact on expected key area from previous test and on different batch of students.

\section{Source of funding}

None.

\section{Conflict of interest}

None.

\section{References}

1. Ramakrishnan M, Sathe AB, Sabnis VA. Item analysis: A tool to increase MCQ validity. Indian J Basic Appl Med Res [Internet] 2017;(6):184-9. Available from: www.ijbamr.com

2. Understanding Item Analyses | Office of Educational Assessment [Internet]. [cited 2019 Nov 18]. Available from: https://www.washington.edu/assessment/scanningscoring/scoring/reports/item-analysis/

3. Ingale AS, A. Giri P, Doibale MK. Study on item and test analysis of multiple choice questions amongst undergraduate medical students. Int J Community Med Public Heal 2017;4(5):1562.

4. Quaigrain K, Arhin AK. Using reliability and item analysis to evaluate a teacher-developed test in educational measurement and evaluation. King Fai Hui S, editor. Cogent Educ [Internet] 2017;4(1). Available from: https://www.cogentoa.com/article/10.1080/2331186X.2017.13 01013

5. Poornima S, Vinay M. The Science of Constructing Good Multiple Choice Questions (MCQs) 1.

6. Kolte V. Item analysis of Multiple Choice Questions in Physiology examination. Indian J Basic Appl Med Res [Internet]. 2015;320. Available from: www.ijbamr.com 